\section{Apert Syndrome: New Treatment and a Perspective for the Future}

\title{
Abstract
}

Treatment the Apert Syndrome is unique, therefore, divergences exist in the priority of the procedures performed by each team. The Apert Syndrome occurs in approximately $1 / 65,000$ births and accounts for $4.5 \%$ of all craniosynostosis. Some changes in Apert Syndrome stand out, such as craniosynostosis and polydactyly.

Keywords

Apert Syndrom, Treatment, Craniosynostosis, Polydactyly

Apert Syndrome is the most widely recognized craniosynostosis syndrome. It was first described by Wheaton' in 1894 and subsequently further cases were reported by Apert. Apert syndrome, named after this French physician "Eugene Apert" who first described it in 1906 and is a relatively uncommon cranio-facial anomaly. [1] It occurs in approximately $1 / 65,000$ births and accounts for $4.5 \%$ of all craniosynostosis $[2,3]$. In case of an affected parent, the condition is transmitted in an autosomal dominant way with the offspring of one affected parent heterozygous for the mutation. [4] Most cases of AS are caused by either one of the two missense mutations in FGFR2 exon 7, i.e., C934G or C937G leading to the amino acid substitutions S252W or P253R, respectively. These mutations are known to enhance ligand-dependent activation of FGFR2 by reducing the dissociation rate between ligands and FGFR2; loss of ligand specificity in turn causes aberrant binding of FGFR2IIIc, a mesenchymal splicing isoform, to FGF7 or FGF10, thereby inducing enhanced differentiation of osteoblasts. $[5,6,7,8]$.

The typical clinical features of Apert syndrome described extensively in the literature include: 1) Craniosynostosis: a wide bony defect possibly extending from glabella to the posterior fontanel and caused by the early closure of the coronal suture, the cranial base and the abs-

Bruno Gonçalves Leite ${ }^{1}$, Ana Beatriz Tavares Filgueiras $^{2}$, Kécia Silva Damasceno ${ }^{2,3}$, Janaina Batista Pereira ${ }^{3}$, Vânia Barbosa do Nascimento ${ }^{3}$, Hiroê Alencar Braga1, Patrícia Gonçalves Pinheiro', Hellen Lúcia Caldas Lins ${ }^{1}$, Modesto Leite Rolim Neto, ${ }^{1,2}$ Cícera Janielly de Matos Cassiano ${ }^{1}$

1 Faculty of Medicine, Estácio - FMJ, Juazeiro do Norte, Ceará, Brazil.

2 Faculty of Medicine, Federal University of Cariri - UFCA, Barbalha, Ceará, Brazil.

3 Pos-graduation Program in Health Sciences, Faculty of Medicine ABC - FMABC, Santo André, SP, Brazil.

Contact information:

Modesto Leite Rolim Neto.

$\equiv$ modestorolim@yahoo.com.br 
ence of the sagittal and metopic sutures; 2) Midface hypoplasia: as the fronto-ethmoidal suture, sphenooccipital and spheno-ethmoidal synchondroses fuse early, both the anterior and posterior parts of the cranial base are short and give rise to hypoplasia of the midface. This is the case in the transverse as well as in the sagittal direction, which result in a skeletal Class III relationship; 3) Cone-shaped calvarium; 4) Skeletal open bite: a large anterior open bite is present in most patients, along with a Class III malocclusion and retruded maxillary teeth; 5) Pharyngeal attenuation: this is also the result of early synostosis of the spheno-occipital synchondrosis, resulting in a short posterior cranial base and thus reduction of the pharyngeal height; 6) Pseudocleft palate with a Byzantine-arch shape: the bilateral swellings of the palatine processes create a midline pseudocleft of the soft tissue; 7) Dental findings: delayed tooth eruption, ectopic eruption of teeth, shovel-shaped incisors, tooth agenesis and severe crowding; 8) Ocular manifestations: proptosis (often asymmetric), hypertelorism and shallow orbitae. Patients often experience visual disturbances which are due to imbalance of the muscles that move the eyes; 9) Syndactyly of hands and feet, or webbing of the fingers and toes: the fused digits are usually separated surgically; however, there can be limited mobility of some fingers due to progressive ossification of interphalangeal joints; 10) Mild intellectual disability may be present in some individuals; 11) Cutaneous manifestations: excessive sweating is a typical characteristic; 12) Gastrointestinal and cardiac malformations may be present in patients with Apert syndrome; 13) Impaired hearing: hearing loss can occur due to recurrent ear infections; 14) Unusual speech characteristics: underdevelopment of the midface, a small nose and an excessively long soft palate can lead to hyponasal resonance. If patients also have a cleft palate, however, then hypernasal resonance will be produced. Speech and language development is also often affected when hearing is impaired. [9-14, 4].
Surgical treatment requires a team approach consisting of neuroradiologist, craniofacial surgeon, pediatric surgeon, pediatric anesthetist, plastic surgeons for hand surgery and orthodontist. $[15,1]$.

Treatment of each patient is unique, therefore, divergences exist in the priority of the procedures performed by each team. Some changes in Apert Syndrome stand out in search term, such as craniosynostosis and polydactyly.

\section{Craniosynostosis}

In 1971, Tessier described the use of the frontofacial advancement to correct the deformity of the Apert skull. His frontofacial advancement was further modified by Ortiz-Monasterio in 1978 into the monobloc osteotomy, which advanced the orbits and the midface together. Van der Meulen used this monobloc to correct orbital hypertelorism in a child with a median facial cleft, and Tessier refined this to the facial bipartition. [16-18, 19].

The ultimate goals of treatment for craniosynostosis are relieving cranial constriction to allow functional brain development and improving or maintaining cosmetic appearance. Various surgical techniques such as frontoorbital advancement (FOA) or total calvarial reconstruction have been described for treating craniosynostosis, which are standard procedures for craniosynostosis because of their postoperative effects on the cranial vault. [20-23, 24]

The incidence of relapse is low when syndromic craniosynostosis is treated with monobloc distraction or Le Fort III midfacial distraction. These procedures are recognised as useful surgical techniques that can yield good morphological and functional results and that can replace conventional methods. According to past reports, each institution seems to be using an external or internal device for distraction based on the surgeon's preference. The external and internal devices appear to be used at even frequencies. However, it is not easy to appropriately 
differentiate their uses, and selection of device type is often a challenge. [25].

The present study used three types of devices in patients according to an algorithm that we developed ourselves (Figure 1). [25]

Distraction techniques with a variety of external and internal distraction systems have been successfully used to advance the midface. However, external distraction devices generally cannot deliver adequate distraction forces for lengthening; as a result, the distraction achieved is limited. On the other hand, internal distraction devices do not allow control of the post fixation distraction vector. We have developed a hybrid facial distraction system (HFDS) leveraging the advantages of external and internal distractiondevices. However, when the advanced maxilla undergoes excessive clockwise rotation and is shifted more downward vertically than the planned position, it might be impossible to pull it back into the planned position (Figure 2). [26-35, 36].

In many craniofacial units, a posterior vault expansion is done as initial surgery in patients with Apert and Crouzon syndromes and craniofrontonasal dysplasia. The conventional technique for posterior vault expansion needs a large dural dissection compared to the spring technique to release the

Figure 1: Algorithm of Early Le Fort III Distraction in Craniosynostosis. [25].

\section{Sindromic craniosynostosis}
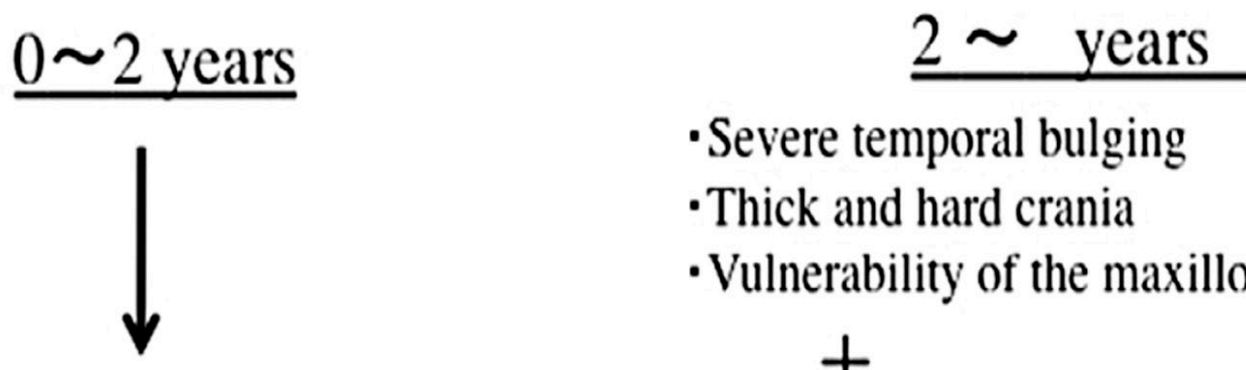

- Severe temporal bulging

- Thick and hard crania

-Vulnerability of the maxillozygomatic suture

\section{Transfacial Pinning Distraction}

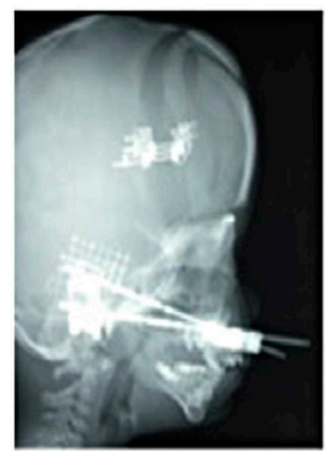

\section{Halo Distraction}

Distraction using internal device

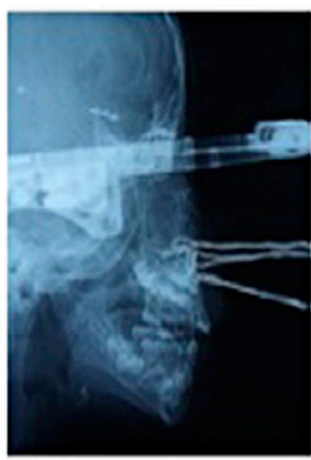

(zygoma-zygoma type)

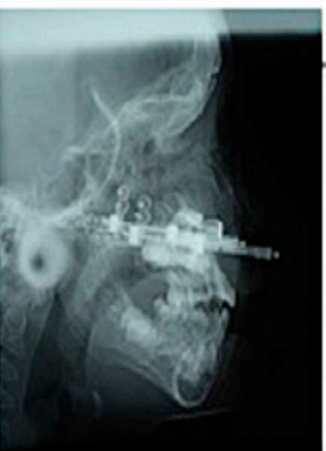


Figure 2: External distraction devices enabling control of distraction vertical vector and maxillary distraction technique with internal and external devices. A, Before procedure. B, Orbital and facial height increased by excessive clockwise rotation of distraction. C, Adequate orbital and facial height achieved by vertical distraction device. D and $E$, The external distraction device enables control of the distraction vector via surgical wires. At the same time, the internal distraction device has an adjustable angle which moves up and down according to the direction of the wires. The angle of the internal distraction device's fixation position on the temporal bone can be altered by 5-15 degrees from side to side. Additionally, the device which can control the direction of the advanced maxilla vertically is attached to the external distraction device. Then, surgical wires are attached to the screws and spindle units after penetrating through the scalp and passed through the inside of the zygomatic arch. The vertical direction of the extended maxilla can be controlled by adjustment of the spindle units. [36].
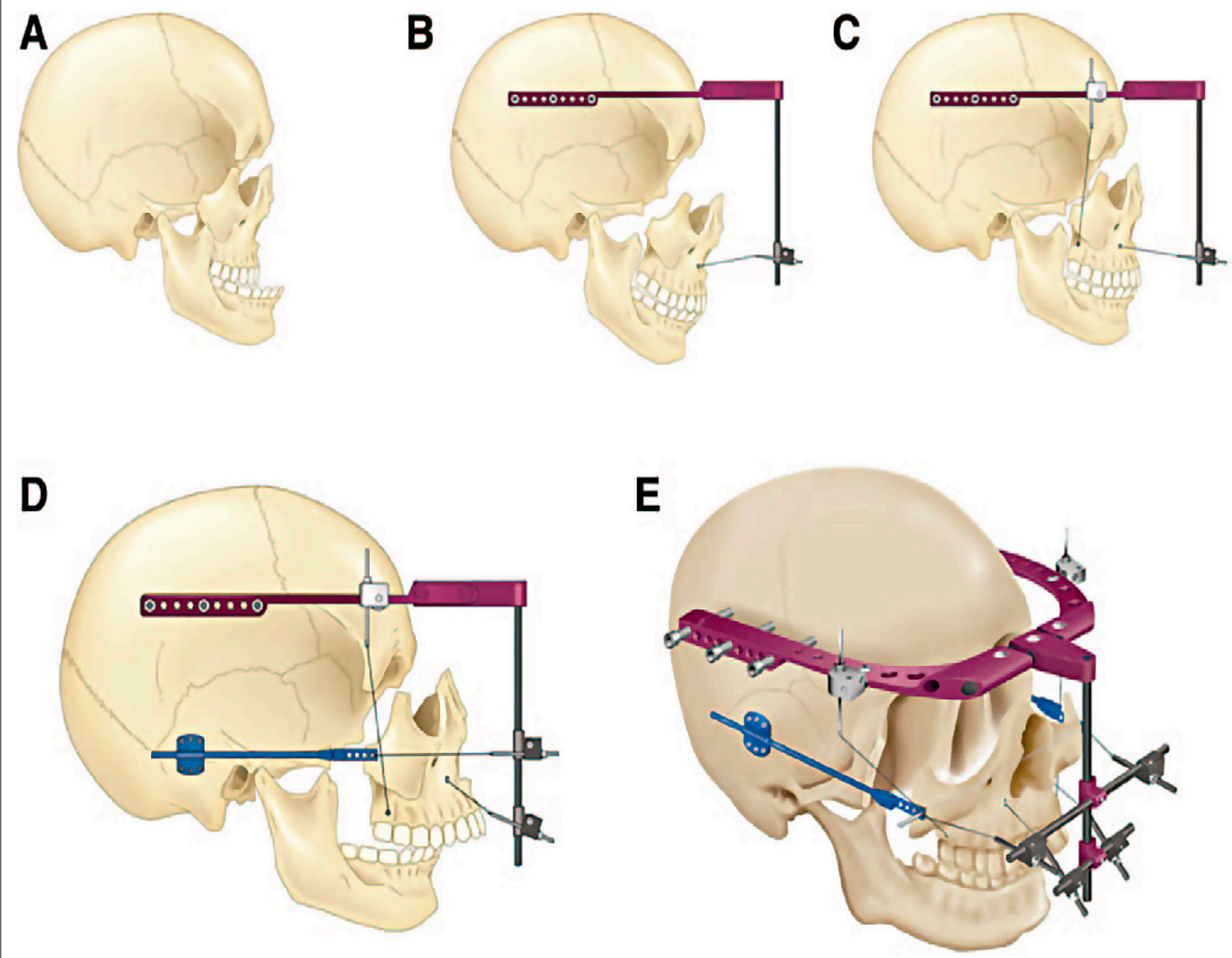
dura from the bone flap; this involves a higher risk for significant blood loss. Furthermore, the amount of push back of the occiput is restricted by the tightness of the skin. These problems have been solved with the introduction of distraction osteogenesisassisted vault expansion. The current technique with internal distractors that protrude through skin incisions has some disadvantages such as pin infection and mechanical problems. Spring-assisted posterior vault expansion is a possible alternative. Spring-assisted expansion was introduced by Lauritzen et al. and has since been used for various indications and types of craniosynostosis. [37-46, 47].

However, calvarial distraction is not without potential downsides: enlargements are limited to a single vector per device, the treatment process is extended from a single day to a number of months, and second operative procedures are necessary for removal of the expansion devices. Issues with expansion devices have also been reported including mechanical breakage and erosion of springs through the bone. $[48,49,50]$. It is thought that posterior vault expansion offers a greater volume increase compared to frontal vault expansion, preserves the facial profile in case of midface hypoplasia, and leaves the frontal part of the skeleton untouched which may reduce the complications of a monobloc or facial bipartition performed at a later age. A monobloc or facial bipartition is indicated in most cases to protect the eyes in case of severe exorbitism, treat obstructive sleep apnea, and for aesthetic reasons. [51, 47]

Our team developed an advancement method using an external transfacial pin and limited osteotomies on the external orbit. No Le Fort III osteotomy was used and the gap between the nose and the skullbase was in this way avoided.

As a consequence, our actual technique did not allow us to correct significantly the anterior open bites, but we did not generate new ones either. On the other hand, it allows to control the distraction vector and to correct it easily in case of disturban- ces. The disadvantage of using external devices resides especially in their social aspect as the child may be stigmatized during this period by his peers and may not be suitable for school classes over 3 to 6 weeks. The anterior scar of the external wires can be between 0.5 and $1.5 \mathrm{~cm}$ long. It can be treated as a scar revision if needed. The other advantages of an external frame are numerous. The procedure is simple and fast, the frame is easily inserted and removed at the end of the protocol in the day of surgery. It is less distressing than the halo frame. There has no risk for intracranial accidental penetration of our device when performing complete vault reshaping. The limited osteotomies and the lack of Le Fort osteotomy avoids communication to the cranial fossa and potential severe complications like infection and CSF leakage. There is also no bleeding from a facial osteotomy. Furthermore, the use of an external device avoids the risk of infection related to intra-focal devices. [52-55, 56].

\section{Polydactyly}

The main goal of surgery for hand anomalies of Apert syndrome patients is to reconstruct the thumb to index finger pulp-topulp pinch to overcome common difficulties in their daily life such as holding a fork or a spoon and buttoning up. $[57,58]$. Various classifications have been used to assist surgeons in planning surgery. The Upton [60] classification is most commonly used; it divides the hand deformity into 3 types that correspond with increasing severity. Type 1 consists of a complex (osseous and soft-tissue) syndactyly of digits 2 through 5, with the thumb free. This is described as the spade hand. A type 2 deformity involves a complex syndactyly of digits 2 through 5 , with an associated simple syndactyly of the thumb. This has been described as the spoon or mitten hand. A type 3 deformity consists of complex syndactyly of digits 1 through 5, with complex syndactyly of the thumb; it has been described as the rosebud hand. [59-61, 62] 
We have developed a protocol for preoperative imaging of the Apert hand that enables visualization of the arterial anatomy to a level distal to the distal interphalangeal joints (Figure 3). This information is used by the surgeon to plan and execute a single-stage syndactyly release of the entire hand, which reduces the total number of operations a child must have. We were able to manipulate 3-dimensional reconstructions of the angiograms to allow operative planning (Figure 3). The images were then analyzed to identify at

Figure 3: Representative images of the 3-dimensional angiograms of the Apert hand deformity. Angiograms of A, B type 1, C type 2, and D type 3 apert hands. [62]
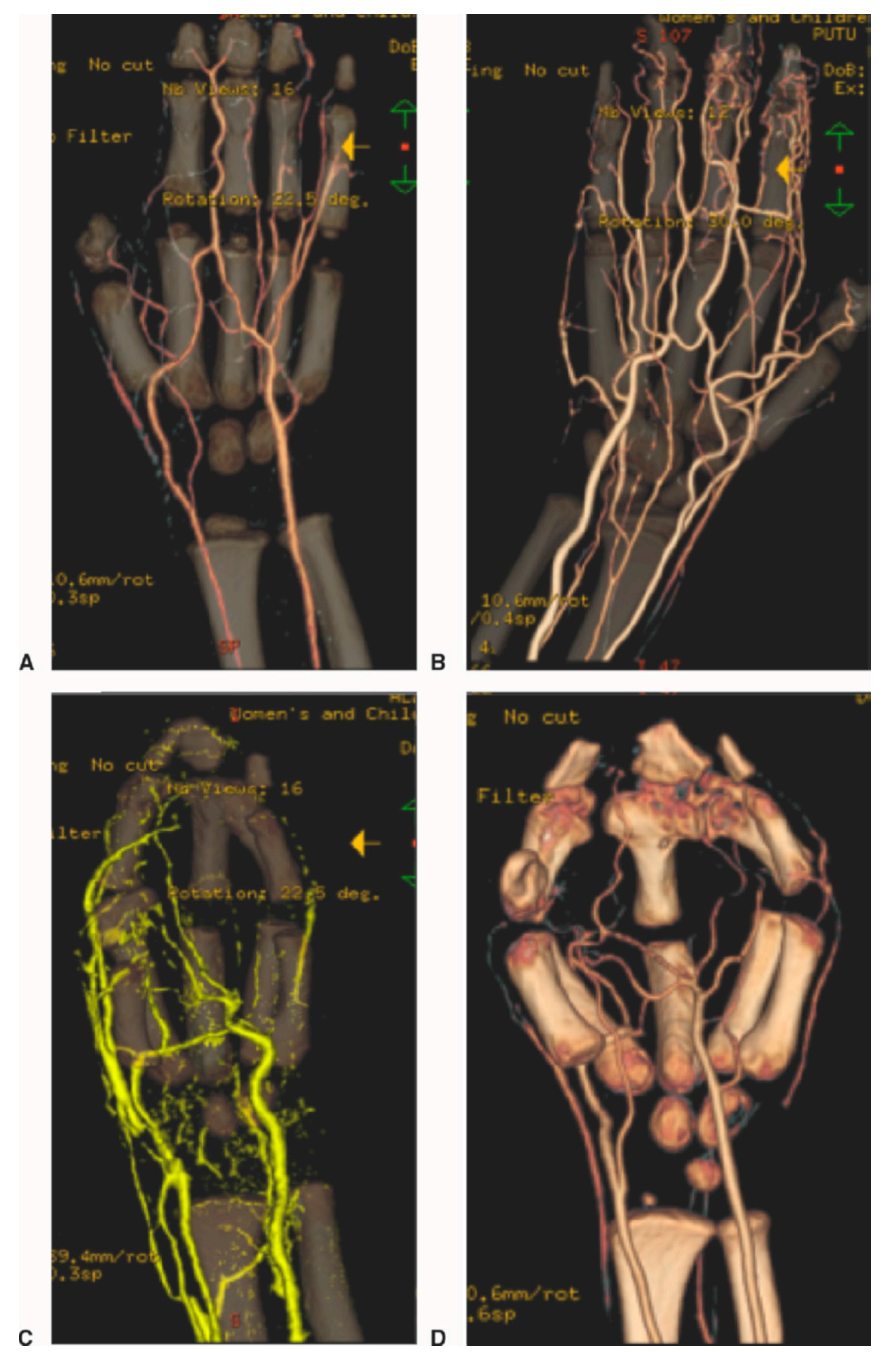

least one artery to each digit, demonstrating continuity of contrast material. The position of these arteries was recorded, and surgical dissection was planned to ensure that each artery was included in the correct digit. Abnormalities in the anatomy were identified and incorporated into the surgical plan. [62].

A single-stage release of the syndactyly provides the benefit to the patient of a single operation and a single recovery period, this means noteworthy savings in terms of hospital bills and accommodation expenses, in addition to the obvious benefit of fewer operations. recovery period. For many of our patients who travel from overseas and remain in our center during the. [62].

After the initial procedures for syndactyly release, when the fact that the range of motion is limited in the second proximal interphalangeal joint is taken into consideration, radial deviation of the thumbs remains as the most important issue for Apert syndrome patients in terms of functional impairment. Because radial deviation of the thumb is associated with the loss of index-to-thumb pulp-to-pulp pinch, these patients may experience limitations in their daily life activities such as problems in buttoning up and holding a spoon. [63, 58].

In this study, instead of the conventional linear approach, a C-shaped osteotomy was performed from radial to ulnar direction to the distal portion of the triangular delta phalanx with care to spare the epiphyseal plate. Planning a C-shaped osteotomy allows the desired rotation while distracting the segments. Moreover, because bone-to-bone contact is not lost and the segments are gliding on each other during distraction, we believe that the risk for fibrous union is lower and the obtained bone quality is better than with the conventional approach. An external fixator is placed using 1 or 2 pins to the proximal portion and 1 pin to the distal side of the osteotomy with care, sparing the epiphyseal plate (Figure 4). In patients whose delta phalanx was hypoplastic, for insertion of proximal pins, the 
Figure 4: A, Schematic of preoperative appearance demonstrating brachydactyly and radial angulation of the thumb. B, Schematic of intraoperative appearance; note the C-shaped osteotomy performed to the distal portion of the triangular delta phalanx with care to spare the epiphyseal plate. C, Schematic of postoperative appearance; the correction of radial angulation and lengthening of the thumb are remarkable. [58]
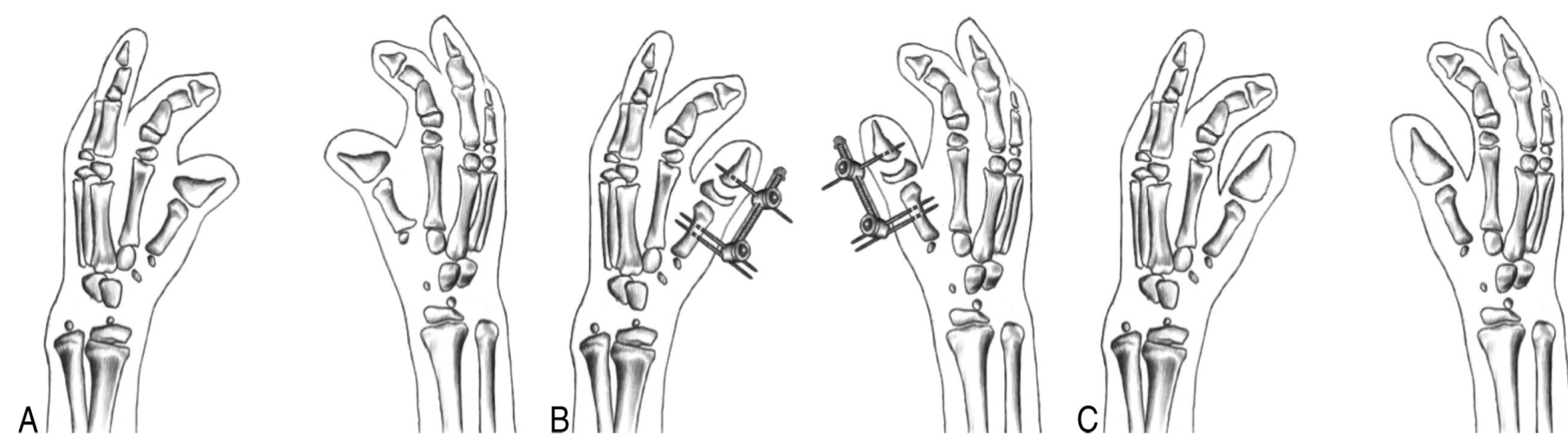

distal portion of the first metacarpal bone was preferred. Pin loosening seems to be the major disadvantage of our procedure because this led to loss of stability of the external fixator in 6 applications of 4 patients. Besides pin loosening in 2 patients, PTI was observed. Another potential disadvantage of distraction is subluxation of the adjacent joint, whereas in the long-term follow-up, this had not been seen in any of our patients. This is probably related to the distraction and adaptation of the soft tissue as well. [58]

\section{Possible Treatment In The Future?}

Fibroblast growth factor receptors (FGFR) 1-4 are members of the tyrosine kinase receptor family, and thus far 22 FGF ligands have been identified. FGFR signaling induces proliferation, migration, differentiation, and survival of many cell types. Apert syndrome is characterized by craniosynostosis and severe bony syndactyly of the hands and feet. It is predominantly caused by missense mutations in FGFR2, which lead to S252W or P253R amino acid substitutions and result in a gain-of-function FGF signaling. [64-66, 67].

Recently, two independent mouse models of Fgfr2 ${ }^{1 / S 252 W}$ and Fgfr2 ${ }^{1 / P 253 R}$ have been established.
Similar to AS patients, both models exhibit premature coronal suture (CS) fusion, midfacial hypoplasia, and a domed skull. [68-70, 74].

These mouse models are used to evaluate novel targets and strategies for treatment of Apert Syndrome. The MEK1 inhibitor PD98059 was shown to reduce CS fusion in calvarial explants from Fgfr2 ${ }^{1 /}$ P253R mice. Both pre- and post-natal administration of the MEK1/2 inhibitor U0126 inhibited AS-like phenotypes in $\mathrm{Fgfr}^{1 / \mathrm{S} 252 \mathrm{~W}}$ male mice, as did gene therapy to express a short hairpin RNA against the Fgfr $2^{1 / S 252 W}$ allele. However, synostosis resumed after withdrawal of the chemical inhibitor, which reflects the postoperative re-synostosis phenomenon frequently observed in syndromic craniosynostosis patients. Inhibitors of other pathways that promote osteoblastic differentiation may provide alternatives for direct inhibition of FGF signaling, but they have not been evaluated in an Apert mouse model. [69, 71, 72, 74].

Our previous study demonstrated that a soluble form of the Apert mutant FGFR2 (sFGFR2IIICS252W), which lacks the transmembrane and cytoplasmic domains, acted as a decoy receptor by competing for ligand binding with FGFRs. This mutant inhibited enhanced osteoblastic differentiation in the 
MG63 osteosarcoma cell line transfected with FGFR2IIICS252W. Furthermore, calvarial osteoblasts derived from FGFR2III $\mathrm{C} 252 \mathrm{~W}$ transgenic mice proliferated and differentiated via highly activated MEK, ERK, and p38 pathways, whereas these pathways were suppressed in calvarial osteoblasts expressing sFGFR2IIICS252W. [67, 73, 74].

Our purified sFGFR2III $\mathrm{C} 252 \mathrm{~W}$ is unique for several reasons. First, we speculate that soluble FGFR2IIIS252W can spread to the whole body through the bloodstream because of its endogenous expression in human tissues. Second, it has potent inhibitory effects towards the pathological conditions of Apert because of the S252W mutation, which causes loss of ligand specificity and reduces ligand dissociation rates; this study is the first to report the use of a soluble receptor carrying a mutation associated with a human congenital anomaly. Third, purified SFGFR2III $5252 W$ not only has binding affinity for Fgf2, but was also shown to dimerize with membranebound or cytoplasmic monomeric FGFR2 in the presence or absence of the S252W mutation, resulting in incomplete dimers that block subsequent intercellular signaling. [74]

Our current strategy, which applied the purified protein to the calvarial tissue by using a nanogelcrosslinked hydrogel system as the protein carrier has several advantages; individual nanogels can store proteins inside their nano spaces and then gradually release proteins locally without any significant change in their biological activities; they do not contain antigens; they are inexpensive. However, many problems must be resolved before this protein is applied in clinical settings for the treatment of Apert patients. Because craniosynostosis typically occurs during fetal life, the safety and effectiveness of FGFR2-based treatment must be tested and an appropriate administration technique should be established using animal experiments in vivo. Some patients with craniosynostosis display recrudescence of bony fusion just after craniectomy; the complex might help block these unfavorable phenomena caused by aberrant FGF/FGFR signaling. Taken together, our data suggested that the appropriate delivery of purified SFGFR2IIICS252W could be an effective method for treating not only AS but also other types of craniosynostosis resulting from aberrant FGF/FGFR signaling. [75, 74]

\section{References}

1. Saritha S, Supriya G, Kumar MP. Apert syndrome (Acrocephalosyndactyly): a case report. Int J Res Med Sci. (2013); 1(1): 36-40.

2. Cohen MM, Jr., Kreiborg S, Lammer EJ, Cordero JF, Mastroiacovo P, Erickson JD, Roeper P, Martinez-Frias ML. 1992. Birth prevalence study of the Apert syndrome. Am J Med Genet 42: 655-659.

3. Morita J, Nakamura M, Kobayashi Y, Deng CX, Funato N, Moriyama K.Soluble Form of FGFR2 With S252W Partially Prevents Craniosynostosis of the Apert Mouse Model. Dev Dyn.. (2014); 243: 560-567.

4. Carpentier S, Schoenaers J, Carels C, Verdonck A. Craniomaxillofacial, orthodontic and dental treatment in three patients with Apert syndrome. Eur Arch Paediatr Dent. (2014); 15: 281289.

5. Wilkie AO, Slaney SF, Oldridge M, Poole MD, Ashworth GJ, et al. (1995) Apert syndrome results from localized mutations of FGFR2 and is allelic with Crouzon syndrome. Nat Genet 9: 165172.

6. Yu K, Herr AB, Waksman G, Ornitz DM (2000) Loss of fibroblast growth factor receptor 2 ligand-binding specificity in Apert syndrome. Proc Natl Acad SciUS A 97: 14536-14541.

7. Yang F, Wang Y, Zhang Z, Hsu B, Jabs EW, et al. (2008) The study of abnormal bone development in the Apert syndrome Fgfr2+/S252W mouse using a 3D hydrogel culture model. Bone 43: 55-63.

8. Yokota M, Kobayashi Y, Morita J, Suzuki H, Hashimoto $Y$, et al. Therapeutic Effect of Nanogel-Based Delivery of Soluble FGFR2 with S252W Mutation on Craniosynostosis. PLoS ONE. (2014); 9(7): e101693.

9. Kreiborg S, Cohen MM Jr. Characteristics of the infant Apert skull and its subsequent development. J Craniofac Genet Dev Biol. 1990; 10: 399-410.

10. Avantaggiato A, Carinci F, Curioni C. Apert's syndrome: cephalometric evaluation and considerations on pathogenesis. J Craniofac Surg. 1996; 7: 23-31.

11. Vadiati Saberi B, Shakoorpour A. Apert syndrome: report of a case with emphasis on oral manifestations. J Dent (Tehran). 2011; 8:90-95. 
12. Letra $A$, de Almeida $A L$, Kaizer $R$, et al. Intraoral features of Apert's syndrome. Oral Surg Oral Med Oral Pathol Oral Radiol Endod. 2007; 103: 38-41.

13. Cohen MM Jr, Kreiborg S. The central nervous system in the Apert syndrome. Am J Med Genet. 1990; 35: 36-45.

14. Cohen MM Jr, Kreiborg S. Cutaneous manifestations of Apert syndrome. Am J Med Genet. 1995; 58: 94-6.

15. Holten IW, Bourne AJ. The Apert syndrome hand: pathologic anatomy and clinical manifestations. Plast Reconstr Surg 1997; 96: 1681-7.

16. van der Meulen JC. Medial faciotomy. Br J Plast Surg 1979 Oct; 32(4):339e42 [PubMed PMID: 534804. Epub 1979/10/01. eng].

17. Tessier P. Apert's syndrome: acrocephalosyndactyly type I. In: Caronni EP, editor. Craniofacial surgery. Boston: Little Brown; 1985. pp. 280e303.

18. Allam KA, Wan DC, Khwanngern K, et al. Treatment of Apert syndrome: a long-term follow-up study. Plast Reconstr Surg 2011 Apr; 127(4): 1601e11 [PubMed PMID: 21187805. Epub 2010/12/29. eng]

19. Crombag GA, Verdoorn MH, Nikkhah D, Ponniah AJ, Ruff C, Dunaway D. Assessing the corrective effects of facial bipartition distraction in Apert syndrome using geometric morphometrics. J Plast Reconstr Aesthet Surg. (2014); 67: e151-e161

20. Lo LJ, Marsh JL, Yoon J, Vannier MW. Stability of fronto-orbital advancement in nonsyndromic bilateral coronal synostosis: a quantitative three-dimensional computed tomographic study. Plast Reconstr Surg 1996;98:393e405 [discussion 406e409].

21. Wong GB, Kakulis EG, Mulliken JB. Analysis of fronto-orbital advancement for Apert, Crouzon, Pfeiffer, and Saethre-Chotzen syndromes. Plast Reconstr Surg 2000; 105: 2314e23.

22. Lwin CT, Richardson D, Duncan C, May P. Relapse in frontoorbital advancement: a pilot study. J Craniofac Surg 2011 Jan; 22(1): $214 \mathrm{e} 6$.

23. Kim YO, Choi JW, Kim DS, et al. Cranial growth after distraction osteogenesis of the craniosynostosis. J Craniofac Surg 2008; 19: $45 \mathrm{e} 55$.

24. Yamaguchi $K$, Imai $K$, Fujimoto $T$, Takahashi $M$, Maruyama $Y$, Sakamoto H, Matsusaka Y. Cranial distraction osteogenesis for syndromic craniosynostosis: long-term follow-up and effect on postoperative cranial growth. J Plast Reconstr Aesthet Surg. (2014); 67(2): e35-41.

25. Mitsukawa N, Kaneko T, Saiga A, Akita S, Satoh K. Early midfacial distraction for syndromic craniosynostotic patients with obstructive sleep apnoea. J Plast Reconstr Aesthet Surg. (2013); 66(9): 1206-11.

26. Britto JA, Evans RD, Hayward RD, et al. Maxillary distraction osteogenesis in Pfeiffer's syndrome: urgent ocular protection by gradual midfacial skeletal advancement. Br J Plast Surg. 1998; 51: 343-349.
27. Chin M, Toth BA. Le Fort III advancement with gradual distraction using internal devices. Plast Reconstr Surg. 1997; 100: 819-830; discussion 831.

28. Molina F, Ortiz Monasterio F, de la Paz Aguilar M, et al. Maxillary distraction: aesthetic and functional benefits in cleft lip-palate and prognathic patients during mixed dentition. Plast Reconstr Surg. 1998; 101: 951-963

29. Polley JW, Figueroa AA. Management of severe maxillary deficiency in childhood and adolescence through distraction osteogenesis with an external, adjustable, rigid distraction device. J Craniofac Surg. 1997; 8: 181-185; discussion 186.

30. Swennen G, Colle F, De May A, et al. Maxillary distraction in cleft lip palate patients: a review of six cases. J Craniofac Surg. 1999; 10: 117-122.

31. Cohen SR. Craniofacial distraction with a modular internal distraction system: evolution of design and surgical techniques. Plast Reconstr Surg. 1999; 103: 1592-1607.

32. Gosain AK, Santoro TD, Havlik RJ, et al. Midface distraction following Le Fort III and monobloc osteotomies: problems and solutions. Plast Reconstr Surg. 2002; 109: 1797-1808.

33. Cohen SR. Midface distraction. Semin Orthod. 1999; 5: 52-58.

34. Polley JW, Figueroa AA. Rigid external distraction: its applicationin cleft maxillary deformities. Plast Reconstr Surg. 1998; 102: 1360-1372; discussion 1373.

35. Kobayashi S, Nishiouri T, Maegawa J, et al. A novel craniofacial osteogenesis distraction system enabling control of distraction distance and vector for the treatment of syndromic craniosynostosis. J Craniofac Surg. 2012; 23: 422-425.

36. Kobayashi S, Fukawa T, Hirakawa T, Maegawa J. A Osteogenesis Distraction Device Enabling Control of Vertical Direction for Syndromic Craniosynostosis. Plastic and Reconstructive Surgery Global Open. (2014); 2(2): e113.

37. Arnaud E, Marchac A, Jeblaoui Y, Renier D, Di Rocco F (2012) Spring-assisted posterior skull expansion without osteotomies. Childs Nerv Syst 28(9): 1545-1549.

38. Davis C, Lauritzen CG (2009) Frontobasal suture distraction corrects hypotelorism in metopic synostosis. J Craniofac Surg 20 (1): 121-124.

39. Davis C, MacFarlane MR, Wickremesekera A (2010) Occipital expansion without osteotomies in Apert syndrome. Childs Nerv Syst 26(11): 1543-1548.

40. Lauritzen C, Sugawara Y, Kocabalkan O, Olsson R (1998) Spring mediated dynamic craniofacial reshaping. Case report. Scand J Plast Reconstr Surg Hand Surg 32(3): 331-338.

41. Lauritzen CG, Davis C, Ivarsson A, Sanger C, Hewitt TD (2008) The evolving role of springs in craniofacial surgery: the first 100 clinical cases. Plast Reconstr Surg 121(2): 545-554.

42. Nowinski D, Saiepour D, Leikola J, Messo E, Nilsson P, Enblad P (2011) Posterior cranial vault expansion performed with rapid distraction and time-reduced consolidation in infants with syndromic craniosynostosis. Childs Nerv Syst 27(11): 19992003. 
43. Serlo WS, Ylikontiola LP, Lahdesluoma N, Lappalainen OP, Korpi J, Verkasalo J, Sandor GK (2011) Posterior cranial vault distraction osteogenesis in craniosynostosis: estimated increases in intracranial volume. Childs Nerv Syst 27(4):627-633.

44. Steinbacher DM, Skirpan J, Puchala J, Bartlett SP (2011) Expansion of the posterior cranial vault using distraction osteogenesis. Plast Reconstr Surg 127(2): 792-801.

45. Swennen G, Schliephake H, Dempf R, Schierle H,Malevez C (2001) Craniofacial distraction osteogenesis: a review of the literature: part 1: clinical studies. Int J Oral Maxillofac Surg 30(2): 89-103.

46. White N, Evans M, Dover MS, Noons P, Solanki G, Nishikawa H (2009) Posterior calvarial vault expansion using distraction osteogenesis. Childs Nerv Syst 25(2): 231-236.

47. de Jong $\mathrm{T}$, van Veelen $\mathrm{ML}$, Mathijssen IM. Spring-assisted posterior vault expansion in multisuture craniosynostosis. Childs Nerv Syst. (2013) May;29(5):815-20.

48. Davis $C$, Windh $P$, Lauritzen CG. Do expansile cranial springs erode through the cranium? J Craniofac Surg 2009; 20: 168170. PubMed PMID: 19165018. Epub 2009/01/24. Eng.

49. Lee JA, Park DH, Yoon SH, et al. Distractor breakage in cranial distraction osteogenesis for children with craniosynostosis. Pediatr Neurosurg 2008;44:216-220. PubMed PMID: 18354261.

50. Fearon JA1, Varkarakis GM, Kolar J. A comparative study of anterior cranial vault distraction versus remodeling. J Craniofac Surg. (2014) Jul; 25(4): 1159-63.

51. Sgouros S, Goldin JH, Hockley AD, Wake MJ (1996) Posterior skull surgery in craniosynostosis. Childs Nerv Syst 12(11): 727733

52. Pellerin P, Capon-Degardin N, Martinot-Duquennoy V, Vinchon M, Dhellemmes P (2001) Mid-facial distraction without osteotomy with a trans-facial pin report of 4 clinical cases. Ann Chir Plast Esthet 46(4): 277-284

53. Coeugniet $E$, Dhellemmes $P$, Vinchon $M$, Wolber $A$, Pellerin P (2012) Midfacial distraction without osteotomy using a transfacial pin and external devices. J Craniofac Surg 23(1): 184-189

54. Yu CJ, Fearon J, Havlik RJ, Buchman SR, Polley JW (2004) Distraction osteogenesis of the craniofacial skeleton. Plast Reconstr Surg 114(1): 1E-20E

55. Breugem CC, Bush K, Fitzpatrick DF (2007) Le Fort III rigid external distraction complicated by intracranial movement of halo fixation pins. Cleft Palate Craniofac J 45(3): 332-336

56. Coeugniet E, Pellerin P, Wolber A, Dhellemmes $P$, Vinchon $M$. Fifteen years of experience with the midfacial distraction without maxillary osteotomy protocol. Childs Nerv Syst. (2014); 30: 681-688

57. Guero S, Vassia L, Renier D, et al. Surgical management of the hand in Apert syndrome. Handchir Mikrochir Plast Chir. 2004; 36: 179-185.
58. Vargel I, Calis M, Cavusoglu T, Ekin O, Oznur A. Application of C-Shaped Osteotomy and Distraction Osteogenesis for Correction of Radial Angulation Deformities of the Hand in Children With Apert Syndrome: Review of 10 Years of Experience. Ann Plast Surg. (2014)

59. Flatt AE. The care of congenital hand anomalies. 2nd ed. St. Louis: Quality Medical Publishing, 1994: 262-270.

60. Upton J. Classification and pathologic anatomy of limb anomalies. Clin Plast Surg 1991; 18: 321-355.

61. Van Heest AE, House JH., Recklin WC. Two-stage reconstruction of Apert acrosyndactyly. J. Hand Surg 1997; 22A: 315.

62. Harvey I, Brown S, Ayres O, Proudman T. The Apert hand-angiographic planning of a single-stage, 5-digit release for all classes of deformity. J Hand Surg Am. (2012); 37(1): 152-8.

63. Chang J, Danton TK, Ladd AL, et al. Reconstruction of the hand in Apert syndrome: a simplified approach. Plast Reconstr Surg. 2002; 109: 465-470; discussion 471.

64. Ornitz DM, Itoh N. 2001. Fibroblast growth factors. Genome Biol 2: 3005.1-3005.12.

65. Eswarakumar VP, Lax I, Schlessinger J. 2005. Cellular signaling by fibroblast growth factor receptors. Cytokine Growth Factor Rev 16: 139-149.

66. Cohen MM, Jr., Kreiborg S. 1996. Suture formation, premature sutural fusion, and suture default zones in Apert syndrome. Am J Med Genet 62: 339-344.

67. Suzuki H, Suda N, Shiga M, Kobayashi Y, Nakamura M, Iseki S, Moriyama K. Apert syndrome mutant FGFR2 and its soluble form reciprocally alter osteogenesis of primary calvarial osteoblasts. J Cell Physiol. 2012 Sep; 227(9): 3267-77.

68. Chen L, Li D, Li C, Engel A, Deng CX. 2003. A Ser252Trp [corrected] substitution in mouse fibroblast growth factor receptor 2 (Fgfr2) results in craniosynostosis. Bone 33: 169-178.

69. Yin L, Du X, Li C, Xu X, Chen Z, Su N, Zhao L, Qi H, Li F, Xue J, Yang J, Jin M, Deng C, Chen L. 2008. A Pro253Arg mutation in fibroblast growth factor receptor 2 (Fgfr2) causes skeleton malformation mimicking human Apert syndrome by affecting both chondrogenesis and osteogenesis. Bone 42: 631-643.

70. Wang Y, Xiao R, Yang F, Karim BO, lacovelli AJ, Cai J, Lerner CP, Richtsmeier JT, Leszl JM, Hill CA, Yu K, Ornitz DM, Elisseeff J, Huso DL, Jabs EW. 2005. Abnormalities in cartilage and bone development in the Apert syndrome FGFR2(p/S252W) mouse. Development 132: 3537-3548.

71. Shukla V, Coumoul X, Wang RH, Kim HS, Deng CX. 2007. RNA interference and inhibition of MEK-ERK signaling prevent abnormal skeletal phenotypes in a mouse model of craniosynostosis. Nat Genet 39: 1145-1150.

72. Holmes G. 2012. Mouse models of Apert syndrome. Childs Nerv Syst 28: 1505-1510. 
73. Tanimoto $Y$, Yokozeki M, Hiura K, Matsumoto $K$, Nakanishi H, Matsumoto T, Marie PJ, Moriyama K. 2004. A soluble form of fibroblast growth factor receptor 2 (FGFR2) with S252W mutation acts as an efficient inhibitor for the enhanced osteoblastic differentiation caused by FGFR2 activation in Apert syndrome. J Biol Chem 279: 45926-45934.

74. Morita J, Nakamura M, Kobayashi Y, Deng CX, Funato N, Moriyama K. Soluble form of FGFR2 with S252W partially prevents craniosynostosis of the apert mouse model. Dev Dyn. 2014 Apr; 243(4): 560-7.

75. Yokota M, Kobayashi Y, Morita J, Suzuki H, Hashimoto Y, Sasaki Y, Akiyoshi K, Moriyama K. Therapeutic effect of nanogelbased delivery of soluble FGFR2 with S252W mutation on craniosynostosis. PLoS One. 2014 Jul 8; 9(7): e101693.

76. Johnson D, Wilkie AO (2011) Craniosynostosis. Eur J Hum Genet 19: 369-376.

\section{Comment on this article:}

\section{$4[8$ in $8+\mathbf{S} P$}

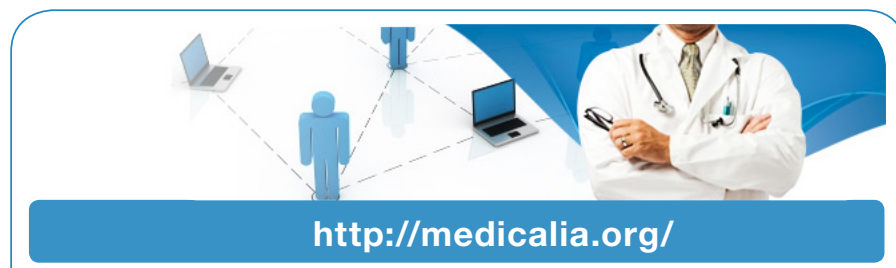

Where Doctors exchange clinical experiences, review their cases and share clinical knowledge. You can also access lots of medical publications for free. Join Now!

\section{Publish with iMedPub}

http://www.imed.pub

International Archives of Medicine is an open access journal publishing articles encompassing all aspects of medical science and clinical practice. IAM is considered a megajournal with independent sections on all areas of medicine. IAM is a really international journal with authors and board members from all around the world. The journal is widely indexed and classified Q1 in category Medicine. 